\title{
A designação de mulher síria refugiada no portal ACNUR/ONU
}

\author{
Giseli Veronêz da SILVA (1) \\ Universidade do Estado de Mato Grosso (UNEMAT)
}

\section{RESUMO}

Este trabalho tem como objetivo apresentar um estudo semântico enunciativo das relações designativas da Formação Nominal Refugiada Síria em um corpus constituído de textos (manchetes/notícias) publicados no portal da ACNUR - Alto Comissariado das Nações Unidas para Refugiados (www.acnur.org), responsável por desenvolver atividades oficiais de prote-

\section{○}

OPEN ACCESS

\section{EDITADO POR \\ - Glaucia Muniz Proença Lara (UFMG) \\ - Marluza da Rosa (UFSM) \\ - Isabelle Tauzin-Castellanos (UBMontaigne) \\ AVALIADO POR \\ - Luiz Francisco Dias (UFMG) \\ - Eliana Sturza (UFSM) \\ DATAS \\ - Recebido: 15/09/2021 \\ - Aceito: 27/10/2021 \\ - Publicado: 07/12/2021}

COMO CITAR

Silva, G. V. (2021). A designação de mulher síria refugiada no portal ACNUR/ONU. Revista da Abralin, v. 20, n. 3, p. 200-220, 2021. ção ao fenômeno mundial "crise dos refugiados". Faremos nossas análises a partir de uma base teórico-metodológica que leva em consideração os estudos enunciativos, de maneira mais específica, nos trabalhos desenvolvidos por Guimarães $(1987 ; 2002 ;$ 2018). Nessa direção, este trabalho, que foi parcialmente resultado de tese de doutorado (SILVA, 2020), investiga os sentidos dessa formação nominal nos enunciados-títulos de notícias do portal da ACNUR, considerada como "uma questão crucial" nas análises, pois "o sentido é produzido na enunciação tomada como acontecimento de linguagem" (GUIMARÃES, 2012, p. 19). Pautados neste princípio, com a realização desta pesquisa, observamos que a formação nominal refugiada síria é reescrita por outras formações nominais determinadas por uma história enunciativa que constitui o sujeito mulher síria refugiada a partir de um memorável específico em cada enunciação.

\section{ABSTRACT}

This work aims to present an enunciative semantic study of the designative relations of the Syrian Refugee Nominal Formation in a corpus consisting of texts (headlines/news) published on the UNHCR portal - United Nations High Commissoner for Refugees, (www.acnur.org), responsible for developing official activities to protect the worldwide phenomenon "refugee crisis". We will make our analyses from a theoretical-methodological 


\section{REVISTA DA ABRALIN}

basis that takes into account the enunciative studies, more specifically, in the works developed by Guimarães (1987; 2002; 2018). In this direction, this work, which was partially the result of a PhD thesis (SILVA, 2020), investigates the meanings of this nominal formation in the headlines of news on the UNHCR portal, considered as "a crucial issue" in the analyses, because "the meaning is produced in the enunciation taken as a language event" (GUIMARÃES, 2012, p. 19). Based on this principle, with this research, we observed that the Syrian Refugee nominal formation is rewritten by other nominal formations determined by an enunciative history that constitutes the Syrian refugee woman subject from a specific memorable in each enunciation.

\section{PALAVRAS-CHAVE}

Refugiadas Sírias. Designação. Semântica da Enunciação. DSD e Sentido.

\section{KEYWORDS}

Syrian Refugees. Designation. Enunciation Semantics. DSD and Sense.

\section{Introdução}

Este trabalho, inscrito no domínio teórico-metodológico da Enunciação (GUIMARÃES, 2002; 2011; 2018) e recortado de uma pesquisa maior (SILVA, 2020), tem como objetivo desenvolver um estudo semântico enunciativo das relações designativas da Formação Nominal Refugiada Síria, em um corpus constituído de textos publicados no website da ACNUR - Agência da ONU para Refugiados. As análises serão desenvolvidas a partir de uma base teórico-metodológica que leva em consideração os estudos enunciativos, como centro de discussão sobre a relação da linguagem com as coisas, o mundo e o real.

O que nos instigou a discutir sobre a designação de refugiada Síria foi o seu viés caracterizador do sujeito. Isto é, observamos, nos enunciados publicados por diferentes meios de comunicação, que o indivíduo, ao ser chamado de refugiado sírio, ganhava um novo sentido, que determinava todos os outros predicados construídos socialmente, na sua individualidade. Ou seja, a mídia não relatava, por exemplo, sobre a professora que, para salvar sua própria vida, precisou sair de seu país e procurar acolhida em outra nação. Diante de tal situação, ser refugiada síria é ganhar um status de domínio sobre todas as outras características que designam esses indivíduos, que são vítimas da chamada "crise dos refugiados". Desse modo, diante dessas observações iniciais, surgiram questões que foram decisivas para a elaboração deste trabalho, o que resultou na principal pergunta: Depois de oito anos de conflitos na Síria, como se designa Refugiada Síria nos textos publicados pela ONU? 


\section{REVISTA DA ABRALIN}

Vale ressaltar que, ao escolher o portal da ACNUR, a agência representante da ONU para tratar das questões sobre os refugiados no mundo, colocamo-nos na posição de leitor, que busca na internet fontes confiáveis que dizem sobre determinado assunto. Dessa forma, o portal da ACNUR significa o meio de representatividade desse grupo de pessoas, e todas as notícias, publicações, manchetes apresentadas nesse portal estão representando um lugar de dizer oficial. Isso foi algo determinante para a escolha do corpus da pesquisa.

Face ao exposto, consideramos importante dizer que o Alto Comissariado da ONU para os Refugiados (ACNUR) foi criado em 1950, por meio da Assembleia Geral das Nações Unidas. A agência teve suas atividades iniciadas em 1951, com a implementação da Convenção relativa ao Estatuto dos Refugiados, assinada em Genebra em 28 de julho de 1951. O objetivo principal da ACNUR era reassentar refugiados europeus que estavam sem lar após a Segunda Guerra Mundial e tinha como propósito contribuir com trabalhos humanitários e com o reestabelecimento social dessas pessoas, tendo como princípio de trabalho o caráter totalmente apolítico.

Entretanto, a Convenção relativa ao Estatuto dos Refugiados assinada em Genebra amparou apenas os refugiados em decorrência dos acontecimentos anteriores a $1^{\circ}$ de janeiro de 1951, isto é, os refugiados que estavam nessa situação devido à Segunda Guerra Mundial. Assim, por resultado dessa marca temporal, surgiu a necessidade de reformular esse documento, uma vez que, desde que a Convenção foi adotada, novas categorias de refugiados foram criadas e, devido à data especificada no documento de 1951, esses novos refugiados não poderiam ser amparados oficialmente. Para esse fim, a ONU criou o Protocolo de 1967, que manteve a definição do que é ser refugiado, mas alterou o documento da Convenção, considerando importante que todos os refugiados abrangidos na definição da Convenção, independentemente do prazo de 1 de janeiro de 1951, possam gozar de igual estatuto. Esse documento é válido mundialmente até os dias atuais.

Diante desse cenário, estatísticas recentes revelam que, nas últimas décadas, os deslocamentos forçados atingiram níveis sem precedentes, ou seja, mais de 67 milhões de pessoas no mundo deixaram seus locais de origem por causa de conflitos, perseguições e graves violações de direitos humanos. Entre elas, aproximadamente 22 milhões cruzaram uma fronteira internacional em busca de proteção e foram reconhecidas como refugiadas, caracterizando, no mundo, uma população estimada em 10 milhões de apátridas, pessoas sem vínculo formal com qualquer país. Essas pessoas, ao chegarem ao país de acolhida, têm seus documentos reformulados e são designadas como refugiadas, designação que determina o modo como são vistas socialmente. Ou seja, as condições históricas que determinam os sentidos de uma palavra estão relacionadas com a significação; em outra acepção, a pessoa refugiada pode ser vista, por exemplo, como foragida ou criminosa.

A questão da significação, dentro da nossa perspectiva teórica, considera que o sentido de uma palavra, de um enunciado, deve ser compreendido além da materialidade textual e linguística, já que consideramos que a questão semântica não está restrita somente a essas relações. O estudo do sentido de uma palavra, de acordo com a forma como pensamos a produção do sentido, deve incluir seu caráter histórico e a exterioridade. 


\section{REVISTA DA ABRALIN}

Nesse sentido, este trabalho investiga os sentidos de "refugiada síria" nos enunciados/notícias do Portal da ACNUR. Para tanto, vale dizer que o sentido, conforme Guimarães (2012, p. 19), "é uma questão crucial" nas análises, pois "o sentido é produzido na enunciação tomada como acontecimento de linguagem" (GUIMARÃES, 2012, p. 19).

\section{Um caminho sem volta: A Guerra na Síria}

A Síria sempre foi cercada de conflitos políticos. Mas foi a partir do movimento da Primavera Árabe que esses conflitos se tornaram um cenário de guerra entre o povo e o governo. Além da questão do modo de governar, a família que está no atual governo instaura uma briga religiosa, pois a identidade religiosa passa a ser assunto de discussão entre os povos dessa nação. Os cidadãos sírios que não compartilham da mesma linha religiosa que a família Al-Assad passam a formar grupos de manifestantes com o objetivo de conseguir a derrubada do poder dos Al-Assad, e esses grupos são designados pela mídia como Rebeldes.

Por outro lado, há grupos que defendem a permanência de Bashar al-Assad no controle político e, dentre esses grupos, estão envolvidos outros países, como a Rússia. O ex-presidente Hafez AlAssad, antes de falecer, construiu estreitos laços políticos com a União Soviética, o que se iniciou com a sua formação militar. Esses laços se transformaram em alguns acordos políticos que se estendem até o atual governo, com o presidente Bashar al-Assad. Por outro lado, temos outros grupos e países que vão contra o atual governo da Síria, dentre eles, os Estados Unidos da América (EUA), país que, de algum modo, articula-se com os manifestantes e se posiciona politicamente contra os ideais de Bashar al-Assad.

Para compreendermos o cenário da guerra na Síria, é importante levar em consideração que, de modo geral, considera-se que, quando o povo pede a derrubada de um governo, é esperado que se coloque alguém no lugar. A imprensa mostrou para a sociedade nacional e internacional que, por muito tempo, houve enunciações como "Dê poder ao povo!", ou "O povo no poder", porém existem diferentes grupos que visam ocupar esse lugar no poder do país, e isso resulta em uma disputa na qual cada grupo apresenta um representante para ocupar esse lugar no controle da Síria.

Após essas manifestações, pessoas com os mesmos ideais políticos ou religiosos formaram grupos pelas redes sociais (Internet) e entraram em uma disputa de poder político com estratégias de manifestações e com o objetivo também de reunir um maior número de manifestantes. Diante disso, a rebelião toma outras dimensões e os rebeldes se nomeiam Exército Livre da Síria, formado, dentre outros cidadãos, por desertores do Exército da Síria.

No final de 2011, cerca de 3 mil soldados e oficiais desertaram do Exército Sírio por discordar das ações do governo e se uniram a civis para formar o Exército de Libertação Síria, ELS (ou Exército Livre da Síria), a maior força armada opositora ao governo al-Assad. Essa oposição é conhecida - e generalizada - no ocidente como "rebeldes" (JUNSKOWSKI, 2017, p. 22). 


\section{REVISTA DA ABRALIN}

Dentre os grupos contra o governo sírio que surgiram nesse período, podemos citar a Frente AlNusra, o Estado Islâmico, o Exército Livre da Síria, os Curdos, entre outros. Desses grupos citados, os Curdos são considerados pelo governo sírio como rebeldes; no entanto, vale dizer que a luta dos Curdos não é contra o regime local, mas para controlar a maioria da população que já é curda, isto é, que faz parte desse grupo étnico do Oriente Médio, para que possam estabelecer e implantar um Estado reconhecido, ou seja, com território próprio, porque esse grupo étnico está espalhado em diferentes nações do Oriente Médio, como a Turquia, o Iraque, parte da Síria e Irã. A disputa dos Curdos por um território é algo predominante na história desse povo, pois, desde a década de 1920, após a Primeira Guerra Mundial, quando houve a divisão do Oriente Médio, a história de resistência dos Curdos é uma questão política constante para os povos dessa região. Isso se deu devido ao fato de que, com a divisão, criaram-se diversos estados. Entretanto, não houve a criação do Estado Curdo, e esse grupo étnico ficou sem um território determinado. Cabe frisar que um dos motivos para a resistência dos Curdos ou - como também é chamado - do Curdistão é a questão populacional, uma vez que esse povo tem mais de 30 milhões de pessoas, sendo conhecido como uma das maiores populações mundiais sem uma nação.

Nessa direção, consideramos que, nesse cenário de conflitos sírios, os Curdos não estão a favor do Governo Assad, porque o governo da Síria faz uso de proibições para conter esse grupo, dentre elas a proibição do dialeto curdo, bem como do uso de nomes de origem curda em crianças nascidas na Síria, a renomeação de lugares curdos com nomes em árabe, enfim, diversos direitos sociais são negados a esses cidadãos por estarem ligados a tal grupo étnico. Por outro lado, vale dizer que os Curdos têm como principal adversário o Estado Islâmico, que é um grupo terrorista inimigo do governo sírio, o que faz, de certo modo, uma aliança entre os Curdos e a Síria.

O Estado Islâmico é mais um grupo contra o governo sírio que nasceu no Iraque em 2003, logo depois do governo ditatorial de Saddam Hussein. Nessa época, a população era dividida em três grupos: Curdos, Xiitas e Sunitas. O conflito aconteceu porque o governo de Saddan Hussen, que era xiita, no período da ditadura repreendia os sunitas, e essas repreensões despertaram a revolta de grande parte da população.

Já em 2014, depois da expansão territorial do Estado Islâmico na Síria, o líder Abdu Bakr AlBaghdadi transformou o exército do Iraque em levante do Estado Islâmico e proclamou a instituição do seu califado (califado é uma forma islâmica de governo baseada em uma monarquia liderada pelo califa, visto como sucessor do profeta Mohamed), responsável por aplicar as leis islâmicas, chamadas de sharia, sobre o território comandado (FERNANDINO, 2017).

Em suma, o Estado Islâmico, o Exército Livre da Síria, entre outros grupos citados anteriormente, constituem uma guerra civil determinada por crises políticas, econômicas, questões religiosas etc. Diante desses acontecimentos, nos deparamos com os efeitos desse cenário de guerra, sendo o principal deles, de acordo com a ONU, a maior crise humanitária já vista por todo o mundo, em que milhares de pessoas se encontram em situação de refúgio, os nomeados Refugiados. 


\title{
REVISTA DA ABRALIN
}

\section{2 É preciso coragem para ser Refugiado: O lugar social dos que buscam proteção}

No início do século XX, a questão dos refugiados passou a ser algo discutido na comunidade internacional, e isso ocorreu devido ao fluxo migratório forçado de pessoas para outras regiões da Europa após a Primeira Guerra Mundial. Em 1919, depois desses acontecimentos, foram criados a Liga das Nações e o Tratado de Versalhes com o intuito de se buscar oficializar laços com diferentes nações para ajudar as vítimas da guerra.

\begin{abstract}
A Conferência de Paz de Paris (doravante, Conferência) foi, para muitos, o marco do século XX que deu fim à Grande Guerra e, finalmente, estabeleceu os fundamentos da paz para uma Europa unida e livre de conflitos, mediada pelo legalismo e institucionalização pioneira da Liga das Nações (doravante, Liga) e, paradoxalmente, pelas punições definidas no Tratado de Versalhes (SAMPAIO; RUSSO, 2011, p. 2).
\end{abstract}

Nesse sentido, o século XX foi o período no qual surgiram diversas discussões acerca do tema dos refugiados, e a Liga das Nações buscou, sobretudo, solucionar o problema do refúgio e também interromper quaisquer planos de uma nova guerra. No entanto, não se pôde conter os acontecimentos futuros, e uma nova guerra surge anos depois: a Segunda Guerra Mundial.

Dessa maneira, no período pós segunda guerra mundial, a Liga das Nações se dissolveu e foi criada, com os mesmos objetivos, a ONU (Organização das Nações Unidas), na qual a questão dos refugiados foi tratada com mais cuidado. A ONU coloca em discussão o futuro dessas pessoas, que sofrem com as consequências das guerras mundiais. Assim, e depois desses encontros oficiais entre as nações para buscar o amparo aos refugiados, surge a necessidade de elaborar documentos com a finalidade de protegê-los e ampará-los. Assim, consideramos também, tal como afirma Le Goff (1990), que "o documento não é qualquer coisa que fica por conta do passado, é um produto da sociedade que o fabricou segundo as relações de forças que aí detinham o poder" (LE GOFF, 1990, p. 546).

Diante dessas considerações, no ano de 1950, diversos debates acerca dessa temática surgem e, no ano seguinte, é implantado, com a Convenção de 1951, o Estatuto do Refugiado, no qual os Estados começaram a ver o tema por uma perspectiva mais ampla, verificando a necessidade de fortalecer a proteção a esses sujeitos para além de seus territórios. Esse documento, além de ser um marco na história do reconhecimento do lugar social do refugiado, é também um acontecimento que determina a legitimação desses cidadãos. Vale dizer que, na posição que assumimos, no lugar de semanticista, "consideramos que os documentos oficiais funcionam como lugar de produção de sentidos. Desse modo, o passado produz sentidos nos acontecimentos registrados como documentos de uma sociedade" (OLIVEIRA, 2019, p. 255-256). Nessa direção, no documento oficial da Convenção de 1951, temos, logo no primeiro parágrafo, a seguinte enunciação:

Considerando que a Carta das Nações Unidas e a Declaração Universal dos Direitos Humanos aprovada em 10 de dezembro de 1948 pela Assembléia Geral afirmaram o princípio de que os seres humanos, sem distinção, devem gozar dos direitos humanos e das liberdades fundamentais (ONU, 1951, p. 1, grifos nossos). 


\section{REVISTA DA ABRALIN}

Constatamos, na citação acima, que o enunciado "afirmaram o princípio de que os seres humanos, sem distinção, devem gozar dos direitos humanos e das liberdades fundamentais" produz sentidos a partir da sustentação argumentativa apresentada no documento publicado pela ONU em 1951. Isso se torna pertinente a partir do momento em que a sociedade toma a ONU como portadora de uma linguagem mundial, fazendo com que as decisões tomadas por essa entidade determinem as regras referentes aos cuidados com as pessoas em situação de vulnerabilidade, bem como a proteção e o bem-estar dos refugiados. Nessa direção, a elaboração desses documentos é resultado dos grandes deslocamentos ocorridos na história moderna, efeito imediato de eventos como a Segunda Guerra Mundial, que gerou um número de aproximadamente 40 milhões de pessoas deslocadas na Europa. Diante desses números, a ONU elaborou documentos com a preocupação de assegurar os direitos humanos desses indivíduos. Como exemplo, tomamos o mesmo documento citado acima, a Convenção de 1951, que define o que é ser refugiado.

2) Que, em conseqüência dos acontecimentos ocorridos antes de $1^{\circ}$ de janeiro de 1951 e temendo ser perseguida por motivos de raça, religião, nacionalidade, grupo social ou opiniões políticas, se encontra fora do país de sua nacionalidade e que não pode ou, em virtude desse temor, não quer valer-se da proteção desse país, ou que, se não tem nacionalidade e se encontra fora do país no qual tinha sua residência habitual em conseqüência de tais acontecimentos, não pode ou, devido ao referido temor, não quer voltar a ele (ONU, 1951, p. 2).

Observa-se que, no texto da convenção, há um marco temporal específico, ou seja, o documento ampara aqueles que ficaram em situação de refúgio antes de $1^{\circ}$ de janeiro de 1951. Há também, nesse mesmo documento, outro artigo que apresenta um marco territorial, ou seja, ele respaldaria apenas as pessoas refugiadas de uma região específica: a Europa, como vemos a seguir:

B. 1) Para os fins da presente Convenção, as palavras "acontecimentos ocorridos antes de $1^{\circ}$ de janeiro de 1951", do art. $1^{\circ}$, seção A, poderão ser compreendidas no sentido de ou a) "acontecimentos ocorridos antes de $1^{\circ}$ de janeiro de 1951 na Europa"; ou b) "acontecimentos ocorridos antes de $1^{\circ}$ de janeiro de 1951 na Europa ou alhures" (ONU, 1951, p. 2).

Conforme o tempo foi passando, percebeu-se a necessidade de estender esse documento, excluindo-se a marcação territorial e temporal, pois, na década de 1950, acreditava-se que o acolhimento ao refugiado consistia em benefícios econômicos, visto que gerava mão de obra abundante nos países de acolhida. Os governos ocidentais acreditavam que a disseminação dos refugiados por todo o mundo iria fomentar uma distribuição mais favorável da população, descongestionando a Europa e beneficiando "democracias ultramarinas" menos desenvolvidas e subpovoadas. No entanto, depois disso, percebeu-se que a questão do refúgio e dos fluxos migratórios não se restringia apenas à região da Europa, porque surgiram outras categorias de refugiados, e a data de $1^{\circ}$ de janeiro de 1951 também não os amparava.

O documento da convenção de 1951 apresenta, então, uma temporalidade específica, que "constitui o seu presente e um depois que abre o lugar dos sentidos, e um passado que não é lembrança ou recordação pessoal de fatos anteriores" (GUIMARÃES, 2002, p. 12). Desse modo, os governos, ao 


\section{REVISTA DA ABRALIN}

fixarem uma data-limite, o fizeram "no sentido de limitar as suas obrigações às situações de refúgio que já eram conhecidas à época, ou às situações que poderiam vir a surgir em seguida em razão de eventos que já haviam acontecido" (ACNUR, 2018, p. 6).

Nessas reuniões e acordos entre os governos para pensar a questão dos refugiados, no mesmo período, em 1950, foi criado o ACNUR, Agência da ONU para Refugiados, por resolução da Assembleia Geral das Nações Unidas. Esse órgão foi designado a tratar especificamente dos Refugiados e iniciou suas atividades em janeiro de 1951, com um mandato inicial de três anos para reassentar refugiados europeus que estavam sem lar após a Segunda Guerra Mundial, e suas ações são amparadas na Convenção de 1951 da ONU sobre Refugiados, que foi reformulada anos mais tarde.

\footnotetext{
Com o tempo e a emergência de novas situações geradoras de conflitos e perseguições, tornou-se crescente a necessidade de providências que colocassem os novos fluxos de refugiados sob a proteção das provisões da Convenção. Assim, um Protocolo relativo ao Estatuto dos Refugiados foi preparado e submetido à Assembleia Geral das Nações Unidas em 1966. Na Resolução 2198 (XXI) de 16 de dezembro de 1966, a Assembleia tomou nota do Protocolo e solicitou ao Secretário-geral que submetesse o texto aos Estados para que o ratificassem. O Protocolo foi assinado pelo Presidente da Assembleia Geral e o Secretário-geral no dia 31 de janeiro de 1967 e transmitido aos governos. Entrou em vigor em 4 de outubro de 1967 (ACNUR, 2020, n.p)
}

Diante disso, o Protocolo de 1967 reformou a Convenção de 1951 e expandiu o mandato do ACNUR (Alto Comissariado das Nações Unidas para Refugiados) para além das fronteiras europeias e das pessoas afetadas pela Segunda Guerra Mundial. Com a ratificação do Protocolo, os países foram levados a aplicar as provisões da Convenção de 1951 para todos os refugiados enquadrados na definição do documento, mas sem limite de datas e de espaço geográfico. Embora esteja relacionado com a Convenção, o Protocolo de 1967 é um instrumento independente, cuja ratificação não é restrita aos Estados signatários da Convenção de 1951 (ACNUR, 2020?). Sobre o trabalho desenvolvido pelo ACNUR, determinado pela Convenção de 1951 e também pelo Protocolo de 1967, o portal da ACNUR diz que,

\footnotetext{
Em muitos países, nossa equipe trabalha junto a outros parceiros em inúmeros locais que vão desde as capitais até campos remotos e áreas fronteiriças. Tentamos promover ou fornecer proteção legal e física, e minimizar a ameaça de violência - incluindo agressão sexual - a que muitos refugiados estão sujeitos, mesmo nos países onde são acolhidos. Também procuramos fornecer abrigo, comida, água e cuidados médicos básicos a todas as pessoas sob o nosso mandato (ACNUR, 2020, n.p).
}

Esse trabalho humanitário do ACNUR/ONU ganhou visibilidade e prestígio social devido à necessidade de os governos tomarem providências quanto ao número significativo de pessoas no mundo que deixaram seus locais de origem por causa de conflitos, perseguições e graves violações de direitos humanos. Em estatísticas recentes, mais de 22 milhões de pessoas cruzaram uma fronteira internacional em busca de proteção e foram reconhecidas como refugiadas. Vale destacar que ao desenvolver seu trabalho humanitário por todo o mundo, o ACNUR já recebeu duas vezes o Prêmio Nobel da Paz (1954 e 1981). 


\section{REVISTA DA ABRALIN}

Sobre o trabalho do ACNUR e os efeitos dos documentos publicados pela ONU para proteção e auxílio de pessoas em situação de refúgio, consideramos que, de acordo com esses documentos, como o Estatuto do Refugiado, é de competência do ACNUR promover instrumentos internacionais para a proteção dos refugiados e supervisionar sua aplicação. Ao ratificar a Convenção e o Protocolo, os Estados signatários aceitam cooperar com o ACNUR no desenvolvimento de suas funções e, em particular, facilitar a função específica de supervisionar a aplicação das provisões desses instrumentos. Assim, a Convenção de 1951 e o Protocolo de 1967, por fim, são os meios através dos quais é assegurado que qualquer pessoa, em caso de necessidade, possa exercer o direito de procurar e receber refúgio em outro país. Entretanto, vale dizer que não é papel da Agência da ONU para Refugiados (ACNUR) substituir o Estado na proteção dada pelas autoridades nacionais, mas sim contribuir e garantir que os países cumpram suas obrigações de conferir proteção aos apátridas, refugiados e a todas as pessoas que buscam refúgio. Com isso, os sistemas nacionais de proteção ao refúgio existem para decidir quais solicitantes precisam de proteção internacional.

A relação dos sírios com toda a política instaurada de proteção à pessoa refugiada se deu devido a todo o percurso de conflitos, e o status de "refugiado sírio" se constituiu a partir de três fases, como mostra Lucena (2017):

\footnotetext{
Uma das consequências do contínuo e crescente fluxo de refugiados, devido à falta de perspectivas para o fim do conflito na Síria, é o aumento do alcance desse processo migratório. Numa primeira fase, tiveram-se os deslocamentos dentro da própria Síria (escalas local e nacional), na segunda fase, a migração para os países vizinhos mais receptivos do Oriente Médio (escala regional). O terceiro momento seria o fluxo em direção aos países europeus (escala continental) e, por fim, o último nível (a escala mundial), quando a corrente migratória começa a se direcionar para regiões mais distantes geograficamente do epicentro da guerra civil, como os países americanos (Estados Unidos, Brasil, Argentina, etc) [...] (LUCENA, 2017, p. 81-82).
}

Como foi exposto acima, observa-se que a crise migratória da Síria teve diferentes fases, primeiramente com os deslocados internos, que são cidadãos que, também por motivos de perseguições, mas sem a oportunidade de sair do país, se deslocam para cidades vizinhas para fugir dos confrontos ou bombardeios que estão ocorrendo perto de suas casas. Essas pessoas se deslocam dentro de seu próprio país pelas mesmas razões que os refugiados. Entretanto, por não existir nenhum órgão responsável pela proteção dessas pessoas, para que elas recebam ajuda igual à dos refugiados, "é necessário que a pessoa ou grupo apresentem as condições necessárias e o reconhecimento e consentimento por parte do governo do país" (ACNUR, 2000, p.3).

Nessa direção, há outras definições para as pessoas que buscam morar em outros lugares, isto é, existem outras categorias de migrações, como o migrante econômico, que se distingue do refugiado, pois, nesse caso, o indivíduo sai de seu país de origem por vontade própria, em busca de melhores condições de vida. Também deve ser distinguido do refugiado o apátrida, que é definido como "toda a pessoa que não seja considerada por qualquer Estado, segundo a sua legislação, como seu nacional" (ONU, 1954, p. 1). 


\section{REVISTA DA ABRALIN}

Essas categorias de migração caracterizam, sobretudo, a maior crise humanitária do mundo, enfatizando-se, de modo específico o refugiado, categoria da qual iremos tratar neste trabalho, direcionando o olhar para a designação, do ponto de vista linguístico, de "refugiado sírio".

Para isso, como foi dito no momento introdutório deste trabalho, analisaremos textos de notícias sobre os refugiados sírios, publicados no site do ACNUR. Ao tomarmos essencialmente o sentido da designação "refugiada síria", compreendemos que "o tratamento da enunciação deve se dar num espaço em que seja possível considerar a constituição histórica do sentido" (GUIMARÃES, 2005, p. 7-8). Diante disso, em tempos de deslocamento forçado, veremos como ser refugiada significa para os enunciados encontrados.

\section{A designação de Refugiada Síria no portal do ACNUR}

O Portal da ACNUR nos apresenta diversas notícias sobre a situação de pessoas refugiadas no mundo todo. Selecionamos para esta análise alguns recortes da categoria de mulheres refugiadas sírias. Desse modo, tomamos enunciados-títulos que apresentam a formação nominal (FN) mulheres refugiadas sírias para vermos a alocução configurada em uma cena enunciativa. Nessa direção, temos a cena enunciativa construída num espaço de enunciação da língua portuguesa, uma vez que o portal da ACNUR no Brasil estabelece essa língua como a língua oficial. Com isso, "o funcionamento da língua no espaço de enunciação se apresenta como uma alocução de L para LT, como uma cena enunciativa" (GUIMARÃES, 2018, p. 55). Dessa forma, consideramos que, para um estudo de base enunciativa, faz-se necessário o estudo da cena enunciativa por se tratar de um fator importante na constituição do sentido. Veremos também o processo de determinação, predicação e argumentação que se apresenta na FN refugiada síria. Na formulação que compõe as notícias do portal da ACNUR, quando se refere e se predica a "mulher síria" em situação de refúgio, verificamos que as descrições tomam um memorável de enunciações que colocam a refugiada síria em diferentes posições sociais, configurando uma politopia na cena enunciativa.

No primeiro recorte, apresentado abaixo, trazemos o enunciado-título publicado no portal da ACNUR no ano de 2018. A notícia é assinada por dois jornalistas, que serão tomados por nós como elementos constituintes da cena enunciativa, que descreveremos logo após a apresentação do recorte. Vejamos como é construída essa relação:

\footnotetext{
1. REFUGIADA SíRIA ABRE LIVRARIA ÁRABE EM ISTAMBUL. Nada, refugiada síria, teve dificuldades de encontrar livros em árabe quando foi para a Turquia, então montou uma biblioteca que oferece a outros refugiados a possibilidade de ler. Por: Charlie Dunmore e Edith Champagne de Istambul, Turquia (ACNUR, 2018, grifo nosso).
}

Observamos, nesse recorte, que os alocutores-jornalistas apresentam dois enunciadores distintos, que podem ser vistos em um primeiro momento no enunciado-título, no qual o lugar de dizer é 


\section{REVISTA DA ABRALIN}

ocupado por um enunciador-universal, e o segundo enunciador pode ser visto no enunciado-lead, tratando-se, então, de um enunciador-individual.

E1 (Univ) - Refugiada síria abre livraria árabe em Istambul.

E2 (Ind) - Nada, refugiada síria, teve dificuldades de encontrar livros em árabe quando foi para a Turquia [...].

Observamos que há um discurso relatado nessa cena, o que pode ser visto quando o al-jornalista emite a seguinte enunciação "Nada, refugiada síria, teve dificuldades de encontrar livros em árabe quando foi para a Turquia". Podemos dizer que, nesse enunciado, temos um al-refugiada que diz do lugar social de mulher refugiada da Síria para outros at-leitores refugiados. Isso ocorre devido à refugiada síria apresentar os seguintes argumentos para o al-jornalista, como pode ser visto na citação abaixo, que está inserida no texto da notícia que segue abaixo do enunciado-título e do enunciado-lead:

Quando a refugiada síria Nada foi para a Istambul há quatro anos, ela logo descobriu que havia uma coisa que sentia mais falta do que qualquer outra. "Quando cheguei, não encontrei nenhum livro em árabe. Eu não trouxe nenhum comigo e era muito caro comprá-los no exterior” (ACNUR, 2018, p. 2).

Veja-se que o Locutor se apresenta em um primeiro momento como enunciador-universal, e na sequência é apresentado por um enunciador-individual (al-refugiada), o qual incide em al-jornalista, utilizando o lugar de enunciador universal para argumentar.

O lugar social de dizer da ACNUR é configurado como um argumento que nos possibilita observar que não se trata de um lugar qualquer, mas sim de um lugar oficial de dizer da agência da ONU, e que, ao apresentar o enunciado "Nada, refugiada teve dificuldades de encontrar livros em árabe", retoma um memorável das adversidades que a pessoa refugiada encontra ao chegar a um país de acolhida. No entanto, tal acontecimento projetou uma futuridade nessa cena, pois, mesmo com as dificuldades, houve a superação e, com isso, projetou-se o acontecimento futuro: abrir uma livraria árabe em Istambul. Nessa direção, observamos que, no enunciado-lead, o al-jornalista complementa com "então montou uma biblioteca que oferece a outros refugiados a possibilidade de ler". Há, nessa enunciação, condições sócio-históricas que a determinam: ao se dizer "oferece a outros refugiados a possiblidade de ler", faz-se, para o alocutário-leitor, a alusão de que há outras pessoas na mesma situação que Nada. O fato de esta refugiada abrir uma livraria leva o alocutário-leitor, a partir da enunciação apresentada, a estabelecer uma relação de sentido entre o acontecimento de abrir a livraria e a refugiada Nada, isto é, o sentido de solidariedade.

Desse modo, podemos dividir o recorte em três enunciados (1a, 1b e 1c) com os seguintes dizeres para uma melhor compreensão:

1a. Refugiada síria abre livraria árabe em Istambul.

1b. Nada, refugiada síria teve dificuldades de encontrar livros em árabe quando foi para a Turquia.

1c. Refugiada Síria montou uma biblioteca que oferece a outros refugiados a possibilidade de ler. 


\section{REVISTA DA ABRALIN}

Podemos dizer que $1 \mathrm{~b}$ e 1c reescrituram por desenvolvimento 1a. Assim, esses enunciados 1a, 1b e 1c "consistentes e independentes, são enunciados enquanto mantêm relações de sentido bem específicas entre si e com outros enunciados do mesmo texto" (GUIMARÃES, 2018, p. 139).

Tomando as características dos enunciados-títulos, para tratar do funcionamento do sujeito, "temos um funcionamento nominal e se apresenta como uma expressão que fala sobre algo que não é da relação eu-tu" (Idem, p. 142).

Podemos parafrasear 1a, tal como ele se integra em 1, por:

1a') Por não encontrar livros em árabe, refugiada síria abre livraria árabe em Istambul para ajudar outros refugiados.

Ao observar esse novo enunciado (1a') que se formou, podemos dizer que o enunciador, se-

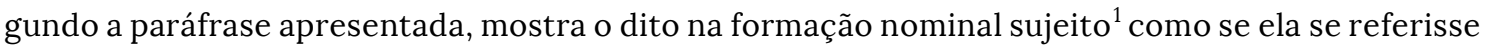
a algo incontestável, ou seja, pelo fato de não ter encontrado livros em árabe em Istambul, a solução da refugiada síria foi a de abrir um comércio para se manter e também para ajudar outros refugiados que buscam por essas leituras. Assim, o al-jornalista toma isso e o apresenta como verdadeiro ao se referir a esse fato apresentado. Desse modo, podemos caracterizá-lo como um Enunciador-universal.

No recorte apresentado, esse enunciador é um lugar de dizer universal, pois a enunciação de "Nada, refugiada Síria abre livraria árabe em Istambul" estabelece o sentido de superação para a mulher refugiada da Síria. Podemos, então, dizer que refugiada síria determina o sentido de empreendedora solidária, e isso só se torna algo diferente dos sentidos pré-estabelecidos socialmente sobre os refugiados porque a notícia ganha um sentido diferente do que dizer "Mulher Síria abre livraria", pois as relações que foram construídas sócio-historicamente, em dado acontecimento, determinaram a formação nominal mulher refugiada síria, e com esse novo acontecimento, ela se constitui por novos sentidos.

Temos então, reescrituras que determinam sentidos para a construção do processo de designação de refugiada síria. Desse modo, Nada reescreve por sinonímia refugiada síria e pelo acontecimento enunciativo sentidos que são determinados por "teve dificuldades em encontrar livros em Árabe". Nessa direção, o al-jornalista menciona que "Nada" montou uma livraria por não encontrar livros no seu idioma. Sendo assim, observamos que "livros" está articulado por coordenação com "montou uma biblioteca" que se articula por incidência com "abre livraria".

Sendo assim, temos o seguinte Domínio Semântico de Determinação:

\footnotetext{
${ }^{1}$ Ver em Dias (2018).
} 


\section{REVISTA DA ABRALIN}

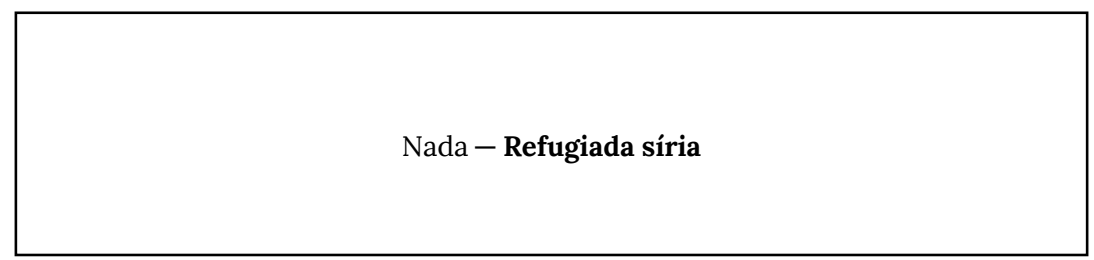

Nada reescreve por sinonímia refugiada síria.

O próximo recorte deste tópico de análise é uma notícia apresentada pelo jornalista Miguel Pachioni, de São Paulo para o portal ACNUR em 2018. A notícia apresenta a história de uma refugiada síria que vive na cidade de São Paulo e se tornou referência de empreendedorismo na gastronomia.

2. REFUGIADA SÍRIA EMPREENDE EM SÃO PAULO E ACUMULA SEGUIDORES PELAS REDES SOCIAIS. Apesar de passar por um período de incertezas, Razan se adaptou à rotina da maior cidade da América do Sul e, com o apoio do ACNUR, se tornou referência de empreendedorismo no segmento de gastronomia. Por: Miguel Pachioni, de São Paulo (ACNUR, 2018, grifo nosso).

Para analisarmos o processo de designação da formação nominal refugiada síria, lançaremos mão do procedimento de reescritura para ver como os elementos do enunciado-título se articulam com os elementos do enunciado-lead e, com isso, constroem sentidos que determinam refugiada síria no portal da ACNUR. Nessa direção, temos no enunciado-título o seguinte: "Refugiada síria empreende em São Paulo e acumula seguidores pelas redes sociais". Podemos dividi-lo em dois enunciados, que aqui trataremos de enunciado A e enunciado B. Observa-se que o enunciado B incide sobre o enunciado A devido à articulação do "empreende", ou seja, estamos diante de uma orientação de argumentatividade (GUIMARÃES, 2018), pois o elemento "empreende" é uma direção dada no texto por uma articulação concessiva.

Faremos agora uma relação entre os textos do enunciado-título e do enunciado-lead para observar como o modo de articulação entre os enunciados determina a construção designativa de refugiada síria. Assim temos:

2a) Refugiada síria empreende em São Paulo e acumula seguidores pelas redes sociais.

2b). Apesar de passar por um período de incertezas, Razan se adaptou à rotina da maior cidade da América do Sul.

2c) [...] com o apoio do ACNUR, refugiada síria se tornou referência de empreendedorismo no segmento de gastronomia.

Há algo importante a se observar, uma vez que o processo de articulação entre os três enunciados acima (2a, 2b e 2c) determinam o sentido de refugiada síria, e a sequência reescreve mais uma vez por desenvolvimento o enunciado-título. Logo, podemos usar a seguinte paráfrase:

2d) Refugiada síria recebe apoio do ACNUR e empreende em São Paulo no ramo da gastronomia. 


\section{REVISTA DA ABRALIN}

Outro ponto que a paráfrase nos possibilita ver é que o "apesar" estabelece sentidos como operador argumentativo, direcionando para outros sentidos, como "passar por períodos de incertezas", que não impediram a adaptação de Razan à rotina da maior cidade da América do Sul (enunciado 2b). E o fato de acumular seguidores (2a) significa que a refugiada síria está conquistando um lugar de prestígio na sociedade, o que pode ser interpretado também como sucesso. Nesse sentido, é importante dizer que temos uma nova formação nominal de refugiada síria predicada pelo sucesso, ou seja, "refugiada síria de sucesso".

Os enunciados que integram esse recorte nos possibilitam dizer que refugiada síria é determinada por "pessoa que enfrenta período de incertezas", "alguém que precisa se adaptar a uma nova rotina", que "recebe ajuda do ACNUR". Por outro lado, a argumentação em j0go nesse recorte nos apresenta novos sentidos para refugiada Síria, entre eles, "aquela que empreende em São Paulo". Há também um novo termo que determina refugiada síria e que, na atualidade, no universo da internet, diz respeito a sua popularidade, seu reconhecimento, sua fama e seu prestígio, pois enunciar "Refugiada síria empreende em São Paulo e acumula seguidores pelas redes sociais" projeta uma futuridade de ascensão profissional; portanto, temos sentidos que designam refugiada síria, que são empreendedora e refugiada síria de negócios, uma vez que as redes sociais são grandes influenciadoras de conteúdos e de propaganda.

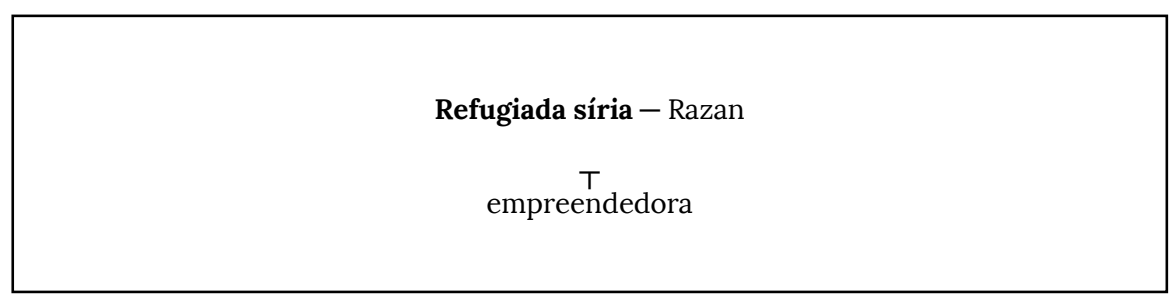

Refugiada síria reescreve por sinonímia Razan e é determinada por empreendedora.

Apresentamos o terceiro recorte para analisar a designação de refugiada síria em uma notícia apresentada pela jornalista Dalia McGill para o portal da ACNUR em 2018. Nela, a formação nominal refugiada síria aparece em uma relação predicativa a start-up, que se trata de um conceito do ramo de empreendedorismo para designar novos negócios. Vejamos o recorte:

3. EM SÃO PAULO, START-UP DE REFUGIADA SÍRIA CRIA OPORTUNIDADES DE NEGÓCIOS PARA OUTROS REFUGIADOS. Projeto Open Taste oferece espaço onde brasileiros descobrem culturas diferentes por meio da gastronomia. Por: Dalia McGill (ACNUR, 2018, grifo nosso).

A primeira coisa a se observar nesse recorte é que a palavra Start-up de refugiada síria é uma nominalização, e esse recurso metafórico pode ser parafraseado do seguinte modo:

3a) Refugiada síria criou um Start-up. 3b) Com isso deu oportunidade de negócios para outros refugiados. 


\section{REVISTA DA ABRALIN}

A partir dessa paráfrase, podemos observar que o al-jornalista enuncia, na notícia do portal da ACNUR, algo sobre o projeto da refugiada síria, isto é, o direcionamento do enunciado da notícia faz com que o leitor seja direcionado para o projeto e não necessariamente para a refugiada síria.

No enunciado acima, observamos, em um primeiro momento, que refugiada síria está em uma relação predicativa com start-up, uma vez que a notícia divulgada por Dania McGill no portal da ACNUR apresenta o start-up como resultado do trabalho desenvolvido por uma "refugiada síria em São Paulo". Nessa direção, tomamos inicialmente a expressão start-up, que é uma palavra da língua inglesa que funciona no espaço de enunciação da língua portuguesa, língua oficial das publicações divulgadas pelo portal da ACNUR no Brasil. Observamos que esse nome ganha sentidos, porque startup é um modelo empresarial moderno, porém já conhecido por pequenos empresários no Brasil. Nessa direção, por mais que a língua oficial das publicações no Brasil seja a língua portuguesa, vale considerar que essa língua se relaciona com outras línguas, como é o caso da cena acima, na qual temos start-up (enunciado-título) e Open Taste (enunciado-lead).

Nessa perspectiva, observemos a configuração da cena enunciativa, na qual temos um alocutorjornalista que, ao divulgar essa notícia para o alocutário-leitor, se coloca no lugar de dizer de um Enunciador-universal, por estar enunciando em um portal oficial da ACNUR. Assim, quando o aljornalista enuncia start-up, ao invés de "recomece", tradução da palavra na língua em que a notícia foi publicada, há uma alusão a um outro lugar de dizer, que seria tomado pelo memorável do ramo empresarial, uma vez que a expressão linguística start-up já é conhecida como um termo empresarial que traz sentidos como um modelo de negócios. Sendo assim, o al-jornalista apresenta uma divisão de enunciadores e, quando diz "start-up de refugiada síria cria oportunidades de negócios para outros refugiados", traz um enunciador-individual, ao avaliar esse novo negócio como "oportunidade" para outros refugiados.

Desse modo, trazer para a mídia o lugar de empreendedorismo, liderança, coloca o lugar social da mulher refugiada síria em uma posição diferente do pré-estabelecido socialmente. Isso nos faz pensar que na configuração da cena enunciativa foi possível perceber que o sentido de mulher refugiada síria foi articulado de modo que a argumentação que resultou em uma mulher bemsucedida fosse construída enunciativamente. Nessa direção, o texto argumenta para que, dentre os sentidos que a FN refugiada síria apresenta, haja um novo sentido construído, isto é, refugiada síria é empreendedora.

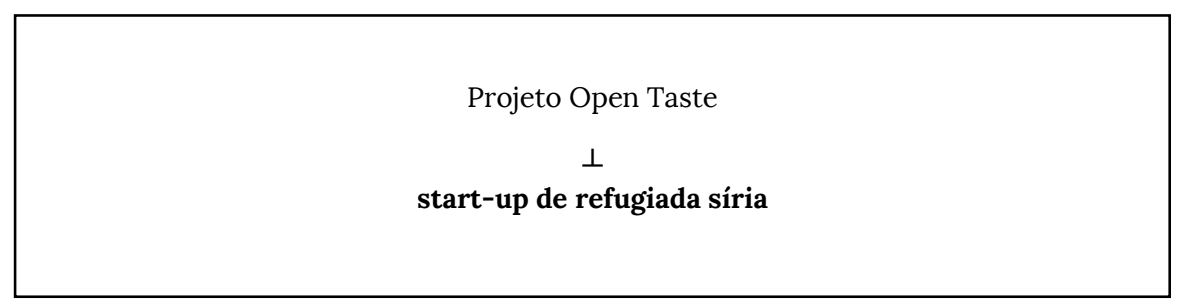

Projeto Open Taste determina start-up de refugiada síria

Vejamos o próximo recorte: 


\section{REVISTA DA ABRALIN}

4. FABRICAÇÃO DE SABÃO OFERECE UM NOVO COMEÇO PARA REFUGIADA SÍRIA EM LUTO. Depois de perder seu filho e sua casa e fugir para a Jordânia, um pequeno ato de bondade ajudou Najwa a construir um negócio de sucesso e a transformar sua vida no exílio. Por: Rima Cherri e Charlie Dunmore, em Zarqa, Jordânia (ACNUR, 2019, grifo nosso).

No recorte acima, há uma relação de predicação que determina o sentido de mulher refugiada síria. Essa relação se estabelece quando o alocutor-jornalista diz: "um novo começo para refugiada síria em luto". Observamos que o alocutor-jornalista assume uma divisão de enunciadores quando apresenta, no primeiro momento (enunciado-título) "Fabricação de sabão oferece um novo começo para refugiada síria em luto", um enunciador-universal e, logo depois, quando diz "um pequeno ato de bondade ajudou Najwa..." estabelece um enunciador-individual, uma vez que dizer "um pequeno ato de bondade" torna-se um modo de avaliação do ato de bondade que a refugiada recebeu.

A relação de predicação entre (a) "Um novo começo" e (b) "refugiada síria em luto", estabelece uma relação de complemento, em que (a) predica (b), ou seja, o enunciado-título pode ser parafraseado como:

4a) Refugiada síria tem um novo começo.

Logo, refugiada síria em luto ganha um novo sentido quando se apresenta, na enunciação, que a fabricação de sabão oferece um novo começo. Podemos pensar em uma direção argumentativa, na qual o luto direciona para o sentido de que a refugiada síria foi derrotada; no entanto, isso é contraditado pelo desenvolvimento do texto, que assume que a refugiada síria venceu o luto e empreendeu com a criação de uma fábrica de sabão. Sendo assim, podemos dizer que, no enunciado-título, o luto direciona para a derrota e, no enunciado-lead, é apresentada uma direção oposta, isto é, a superação. Isso nos possibilita dizer que, apesar das perdas, do luto e da situação de refúgio, a mulher refugiada síria não se entregou às dificuldades e construiu "um negócio de sucesso" no exílio, a partir da fabricação de sabão.

Nessa direção, observamos que a FN inicial refugiada síria é determinada pela expressão "em luto" e, com isso, cria-se, no espaço enunciativo do portal da ACNUR, mais uma FN para refugiada síria, dessa vez especificada por "em luto". Assim, o termo, ao se articular, de um lado, com refugiada síria e, de outro, com "luto" estabelece uma relação de articulação que direciona para uma argumentatividade que nos permite dizer do estado ou da situação em que a refugiada síria se encontra. Ou seja, o "luto", nesse caso, não significa, no funcionamento dessa articulação, somente a perda do filho; significa também o sentimento da "perda de sua casa e fugir para a Jordânia". 


\section{REVISTA DA ABRALIN}

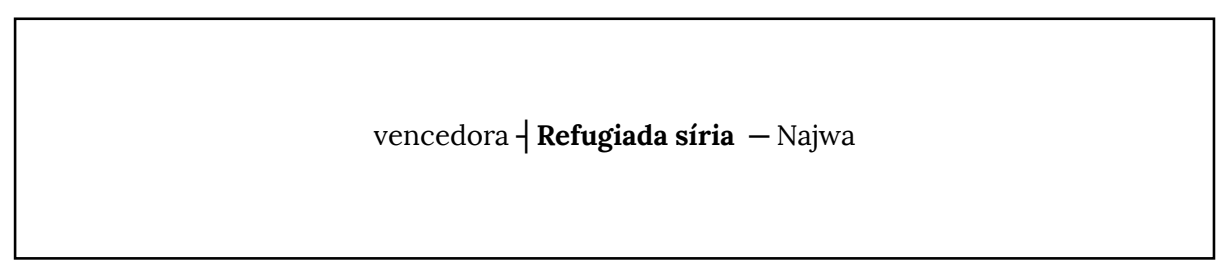

Vencedora determina o sentido de refugiada síria que é reescrita por sinonímia em Najwa.

Outro aspecto importante na relação semântica em que o enunciado se configura é a relação de articulação no próprio texto. Vejamos como os sentidos de refugiada síria se configuram no recorte a seguir:

5. 145 MIL REFUGIADAS SÍRIAS SÃO CHEFES DE FAMÍLIA E LUTAM PARA SOBREVIVER. Mais de 145 mil famílias de refugiados sírios vivendo no Egito, Líbano, Iraque e Jordânia são chefiadas por mulheres que enfrentam sozinhas a luta pela sobrevivência (ACNUR, 2014, grifo nosso).

O quinto recorte traz uma cena enunciativa na qual o al-ACNUR apresenta uma estatística que diz: 145 mil refugiadas sírias são chefes de família. Veja-se que a estatística "145 mil refugiadas sírias" é predicada por "chefes de família" que, por sua vez, é predicado por "enfrentam a luta por sobrevivência”. Essa relação de predicação é possível devido à relação de articulação estabelecida no texto. Ainda desse lado observa-se a articulação sinonimicamente com "145 mil famílias de refugiados sírios", que recebe a predicação de "são chefiadas por mulheres que enfrentam sozinhas a luta pela sobrevivência" e "chefes de família" ainda estabelece uma relação sinonímica com "mulheres".

Algo interessante a se observar é a relação de sentido que esse enunciado produz. Ou seja, não é mais um caso específico de mulher refugiada da Síria que consegue conquistar sua independência ou que consegue dar um novo sentido à situação de refúgio. O número de 145 mil mulheres refugiadas que são chefes de família, além de ser um número que prende a atenção do alocutário-leitor, determina os sentidos para as mulheres sírias, fazendo com que elas sejam vistas como mulheres fortes e determinadas, de modo que a situação vulnerável de estar refugiada não seja algo que protagonize sua história, uma vez que a superação é algo mais característico desse grupo de mulheres.

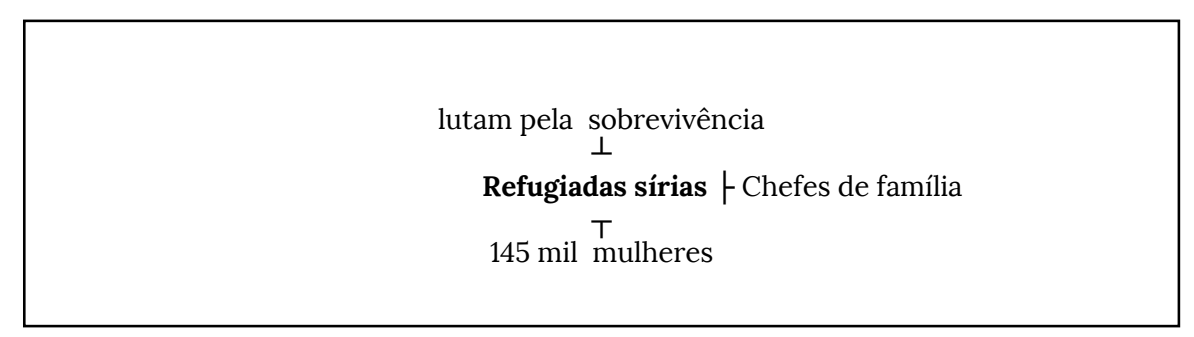

FN Refugiadas sírias é determinada por 145 mil mulheres e também por chefes de família e lutam pela sobrevivência.

O portal da ACNUR, no ano de 2019, publicou também outra notícia, na qual destaca a mulher refugiada da Síria e a coloca na posição social de líder. Vejamos o enunciado a seguir: 


\section{REVISTA DA ABRALIN}

6. REFUGIADA SÍRIA DESAFIA TRADIÇÕES NO PAPEL DE LÍDER COMUNITÁRIA. Em uma posição tradicionalmente ocupada por homens, Alya traz os valores da sua criação para liderar e orientar comunidade de refugiados sírios no Líbano. Por: Dalal Mawad, Vale do Beca, Líbano (ACNUR, 2019, grifo nosso).

Antes de estar no lugar social de mulher refugiada, a mulher síria culturalmente não tem um papel de liderança em seu país de origem; no entanto, vê-se que esse modo de designar a mulher síria nas reportagens da ACNUR faz com que a refugiada síria seja mostrada de forma diferente. Por isso, podemos observar que o alocutor-jornalista diz que "Refugiada síria desafia tradições no papel de líder comunitária". Assim, ao enunciar "desafia tradições", o alocutor-jornalista retoma o memorável de que na Síria a mulher é submissa e vista como propriedade de seu marido, bem como estatísticas publicadas pela ONU de que a Síria está entre os 10 países nos quais a mulher sofre algum tipo de assédio. Podemos dizer que, nessa cena, há uma divisão de enunciadores: o al-jornalista apresenta, no enunciado-título, um enunciador-universal e, no segundo momento, com o enunciado-lead, um enunciador-genérico quando diz "Em uma posição tradicionalmente ocupada por homens...". Com isso, dizer que uma mulher síria ocupa o lugar social de "líder comunitária" faz com que haja uma ressignificação do papel social da mulher Síria, o que leva, por sua vez, à constituição de uma nova expressão "Refugiada síria líder" comunitária e constitui uma nova posição que determina refugiada síria. Ou seja, ressignifica o papel da mulher síria.

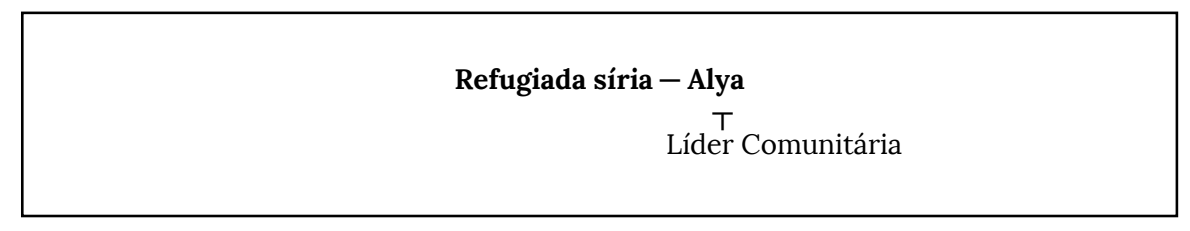

Refugiada síria está em sinonímia com Alya e é determinada por Líder comunitária.

Ainda em 2019, a ACNUR publicou uma reportagem na qual o enunciado-título apresenta a seguinte enunciação:

7. REFUGIADA SÍRIA ENSINA RECEITA A PAOLA CAROSELLA NO TASTY DEMAIS. Vídeo faz parte de iniciativa da Agência da ONU para Refugiados para valorização da troca cultural de refugiados com países que os acolheram (ACNUR, 2019, grifo nosso).

A relação de sentidos presente no enunciado-título acima marca um acontecimento de linguagem que em sua história enunciativa nos permite fazer uma relação de predicação entre refugiada síria e o ato de "ensinar uma receita a Paola Carosella no Tasty Demais". Esse enunciado é caracterizado por apresentar uma temporalidade específica, pois nos permite dizer que, ao chegar ao Brasil, uma mulher refugiada compartilha seus conhecimentos culinários com uma das grandes celebridades gastronômicas do Brasil, que é a chefe de cozinha Paola Carosella. O enunciado se torna pertinente, uma vez que a refugiada síria citada na notícia da ACNUR é uma mulher que, ao chegar ao Brasil, empreendeu e se tornou referência na internet por ensinar receitas de seu país de origem e também por comercializar esses alimentos no país de acolhida, o Brasil. 


\section{REVISTA DA ABRALIN}

Consideramos um aspecto importante para esse acontecimento o fato de refugiada síria ser predicada por "ensina receita a Paola Carosella no Tasty Demais". A expressão enunciativa "ensina receita a Paola Carosella" apresenta o sentido de que uma mulher refugiada ensina culinária para uma chefe de cozinha estrelada. Ou seja, refugiada síria é um nome que não só fala de algo ou alguém; refugiada síria, nesse recorte, fala de algo que se apresenta a partir do lugar social de dizer. Isso pode ser melhor compreendido com a paráfrase a seguir:

7a) Refugiada síria ensina famosa chefe de cozinha a fazer comida árabe.

7b) Paola Carosella e Refugiada síria trocam experiências culinárias em canal culinário do Youtube.

\section{Considerações Finais}

Ao tomarmos a designação mulher refugiada síria, observamos que há uma quebra no estereótipo de que a mulher é frágil ou que depende da figura do marido para sobreviver. Nos recortes apresentados, observou-se que a mulher síria foi designada com sentidos que determinaram a configuração de uma imagem de mulher independente, forte e que soube lidar com as dificuldades que estão por trás do título de refugiado e também de mulher.

Com este estudo, objetivamos mostrar que não basta apenas saber o significado da palavra, expressão ou formação nominal; é necessário que vejamos seu funcionamento na relação de integração no texto em que está inserida. Isso faz com que essa palavra esteja intrinsecamente ligada ao sentido do enunciado, e são essas relações que nos interessam. Assim, o processo de articulação do texto possibilita trabalhar com o enunciado de um modo que os sentidos do recorte determinam o sentido da palavra analisada. "De certo modo, podemos dizer que, semanticamente, toda relação de predicação é, em certa medida, pelo menos, uma relação de determinação e vice-versa" (GUIMARÃES, 2007, p. 78). Ou seja, "o sentido de um elemento linguístico tem a ver com o modo como este elemento faz parte de uma unidade maior ou mais ampla" (GUIMARÃES, 2005, p. 7). Dessa forma, a enunciação é vista como um acontecimento, que instaura sua própria temporalidade, e é nessa enunciação que se dá a relação do sujeito com a língua.

\section{REFERÊNCIAS}

ACNUR. 145 mil refugiadas sírias são chefes de família e lutam para sobreviver - ACNUR Brasil. UNHCR-ACNUR, 08 julho 2014. Disponivel em: <https://bitly/2LL6zVz>. Acesso em: 16 setembro 2019.

ACNUR. Em São Paulo, start-up de refugiada síria cria oportunidades de negócios para outros refugiados - ACNUR Brasil. UNHCR-ACNUR, 30 maio 2018. Disponivel em: <https://www.acnur.org/portugues/2018/05/30/em-sao-paulo-startup-de-refugiada-siria-cria-oportunidades-de-negocios-para-outros-refugiados/1/4>. Acesso em: 16 setembro 2019. 


\section{REVISTA DA ABRALIN}

ACNUR. Refugiada síria abre livraria árabe em Istambul - ACNUR Brasil. UNHCR-ACNUR, 21 maio 2018. Disponivel em: <https://www.acnur.org/portugues/2018/05/21/refugiada-siria-abre-livraria-arabe-em-istambul/1/3>. Acesso em: 16 setembro 2019

ACNUR. Refugiada síria empreende em São Paulo e acumula seguidores pelas redes sociais - ACNUR Brasil. UNHCRACNUR, 15 março 2018. Disponivel em: <https://www.acnur.org/portugues/2018/03/15/refugiada-siria-empreende-emsao-paulo-e-acumula-seguidores-pelas-redes-sociais/1/3>. Acesso em: 16 setembro 2019.

ACNUR. ACNUR e Globo Livros promovem debate com professora síria na semana de comemoração do Dia Mundial do Refugiado - ACN.... UNHCR-ACNUR, 13 junho 2019a. Disponivel em: <https://bit.ly/3g7C3TC>. Acesso em: 16 setembro 2019.

ACNUR. Fabricação de sabão oferece um novo começo para refugiada síria em luto - ACNUR Brasil. UNHCR-ACNUR, 11 março 2019c. Disponivel em: <https://www.acnur.org/portugues/2019/03/11/fabricacao-sabao-novo-comecorefugiada-siria/1/4>. Acesso em: 16 setembro 2019

ACNUR. Refugiada síria desafia tradições no papel de líder comunitária - ACNUR Brasil. UNHCR-ACNUR, 13 junho $2019 f$. Disponivel em: <https://www.acnur.org/portugues/2018/06/13/refugiada-siria-desafia-tradicoes-no-papel-de-lidercomunitaria/1/3>. Acesso em: 16 setembro 2019.

ACNUR. Refugiada síria ensina receita a Paola Carosella no Tasty Demais - ACNUR Brasil. UNHCR-ACNUR, 18 junho $2019 \mathrm{~g}$. Disponivel em: <https://www.acnur.org/portugues/2019/06/18/refugiada-siria-ensina-receita-a-paola-carosella-notasty-demais /1/3>. Acesso em: 16 setembro 2019.

ACNUR. Convenção de 1951, 2020? Disponivel em: <https://bit.ly/377u19b>. Acesso em: 2020

DIAS, L. F. Enunciação e relações linguísticas. Campinas: Pontes, 2018.

FERNANDINO, C. C. C. A expansão do Estado Islâmico no Iraque e na Síria. Fronteira, Belo Horizonte, 16, 2017. 21. Disponível em: <https://bit.ly/3dE0bLX>. Acesso em: fevereiro 2020

GUIMARÃES, E. Semântica do acontecimento: um estudo enunciativo da designação. Campinas: Pontes, 2002.

GUIMARÃES, E. Análise de texto - Procedimentos, análises e ensino. 2. ed. São Paulo: Hucitec, 2017.

GUIMARÃES, E. Semântica: enunciação e sentido. Campinas: Pontes, 2018

JUNSKOWSKI, B. L. SÍRIA: HISTÓRIAS DA GUERRA. Universidade Federal do Paraná, Curitiba, 2017. p. 76

LE GOFF, J. História e memória. Tradução Bernardo Leitão [et al.] - Campinas: Editora da UNICAMP, 1990.

LUCENA, G. G. D. A geopolítica da guerra civil síria e suas implicações para o Brasil. Universidade de Brasília, Brasília, 2017. p. 146.

OLIVEIRA, R. R. R. D. A "Ocupação e a "Civilização" no movimento dos sentidos designação, espaço de enunciação, e argumentação. In: PRIA, A. D., et al. (Org.). Estrutura, acontecimento e formação: os sentidos do político nos estudos da linguagem. Campinas: Pontes, 2019. p. 329.

ONU. Convenção Relativa ao Estatuto dos Refugiados 1951. [S.l.]. 1951

ONU. Convenção sobre o Estatuto dos Apátridas. Nova Iorque, p. 13.1954.

SAMPAIO, A. L.; RUSSO, G. A liga das nações: Uma Perspectiva Europeia. In: Cadernos de relações internacionais, v. 4, n. .1, 2011. 


\section{REVISTA DA ABRALIN}

SILVA, G. V. da. A crise na Síria: o processo de designação de Refugiado Sírio no Portal do Alto Comissariado das Nações Unidas para Refugiados (ACNUR). 2020. 130f. Tese (Doutorado em Linguística) - Faculdade de Educação e Linguagem, Universidade do Estado de Mato Grosso, Cáceres, 2020. 